\title{
The Effect of Moderate Salinity on Nitrate Leaching from Bermudagrass Turf: A Lysimeter Study
}

\author{
D. C. Bowman - Dale A. Devitt • W. Wally Miller
}

Published online: 23 December 2006

C) Springer Science + Business Media B.V. 2006

DOI: DOI 10.1007/s11270-006-9110-5; published in WATE 175, pp 49-60

The artwork for Figs. 2 and 3 is incorrect and is a repeat of the artwork in Fig. 1 of this paper. The captions are correct.
Below are the correct figures printed together with the proper captions.

The online version of the original article can be found at http://dx.doi.org/10.1007/s11270-006-9110-5.

D. C. Bowman $(\bowtie)$

Department of Crop Science,

North Carolina State University,

Box 7620, Raleigh, NC 27695, USA

e-mail: dan_bowman@ncsu.edu

D. A. Devitt

Department of Biological Sciences,

University of Nevada, Las Vegas, NV 89154, USA

W. W. Miller

Department of Environmental and Resource Science,

University of Nevada, Reno, NV 89557, USA 
Fig. 1 Electrical conductivity of a the leachate and b saturated paste extracts of soil containing bermudagrass irrigated with water at three salinity levels $(0.1,3.0$ and $6.0 \mathrm{dS} \mathrm{m}^{-1}$ ). Electrical conductivity values of the leachate are based on the last sampling date of each month and are averaged across nitrogen $(\mathrm{N})$ treatments. Saturated paste extracts were obtained from soil sampled at the conclusion of the experiment (Dec. 18). Bars on data points represent the standard error of the mean $(n=12)$

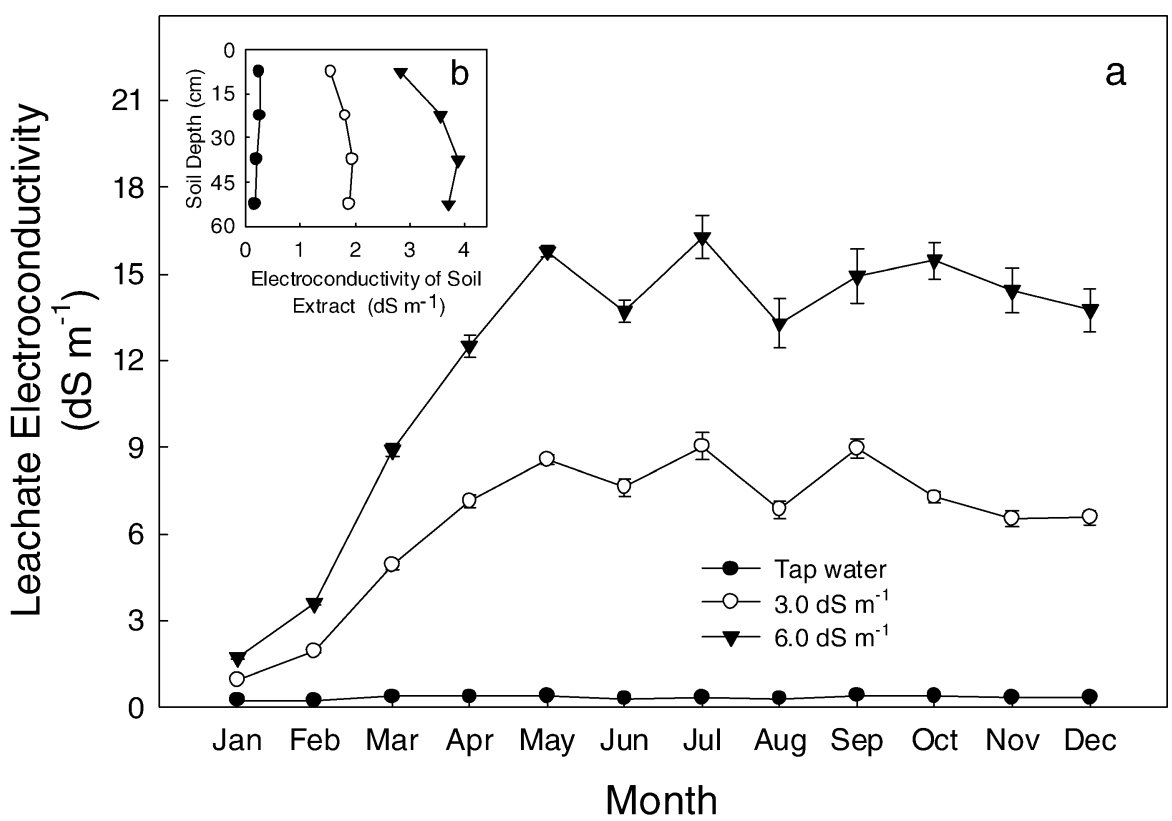

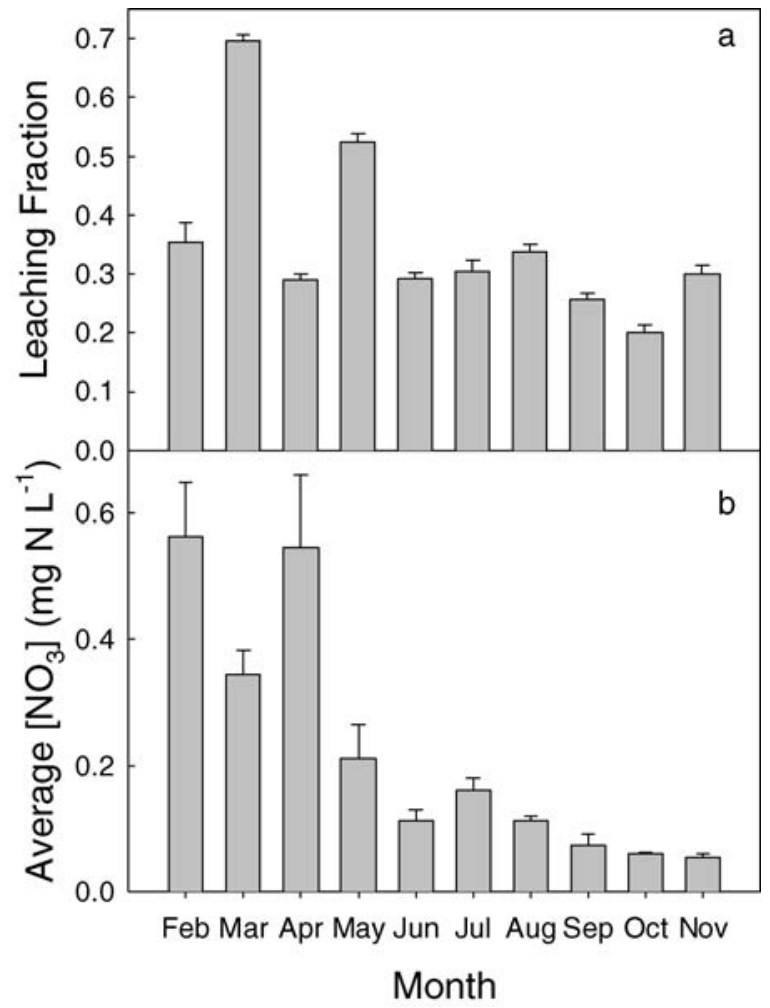

Fig. 2 Average monthly leaching fraction (a) and $\mathrm{NO}_{3}-\mathrm{N}$ concentration in the leachate (b) for columns of bermudagrass fertilized with 25,50 or $75 \mathrm{~kg} \mathrm{~N} \mathrm{ha}^{-1} \mathrm{mo}^{-1}$ and irrigated with water at three salinity levels $\left(0,3.0\right.$ and $\left.6.0 \mathrm{dS} \mathrm{m}^{-1}\right)$. Values are averaged across nitrogen $(\mathrm{N})$ and salinity treatments. Error bars represent the standard error of the mean $(n=36)$ 
Fig. 3 Cumulative $\mathrm{N}$ harvested in the leaf clippings of bermudagrass grown at three nitrogen levels $(25,50$ or $75 \mathrm{~kg} \mathrm{~N}$ $\mathrm{ha}^{-1} \mathrm{mo}^{-1}$ ) over an 11month period. Values are averaged across salinity treatments $(n=12)$. Linear regression lines are plotted for each $\mathrm{N}$ treatment, with the slope representing the rate of $\mathrm{N}$ recovery in clippings. The numerical value adjacent to each curve represents the long-term $\mathrm{N}$ recovery, expressed as a percentage of total $\mathrm{N}$ applied during the experimental period. For all three regressions, $P<0.0001$

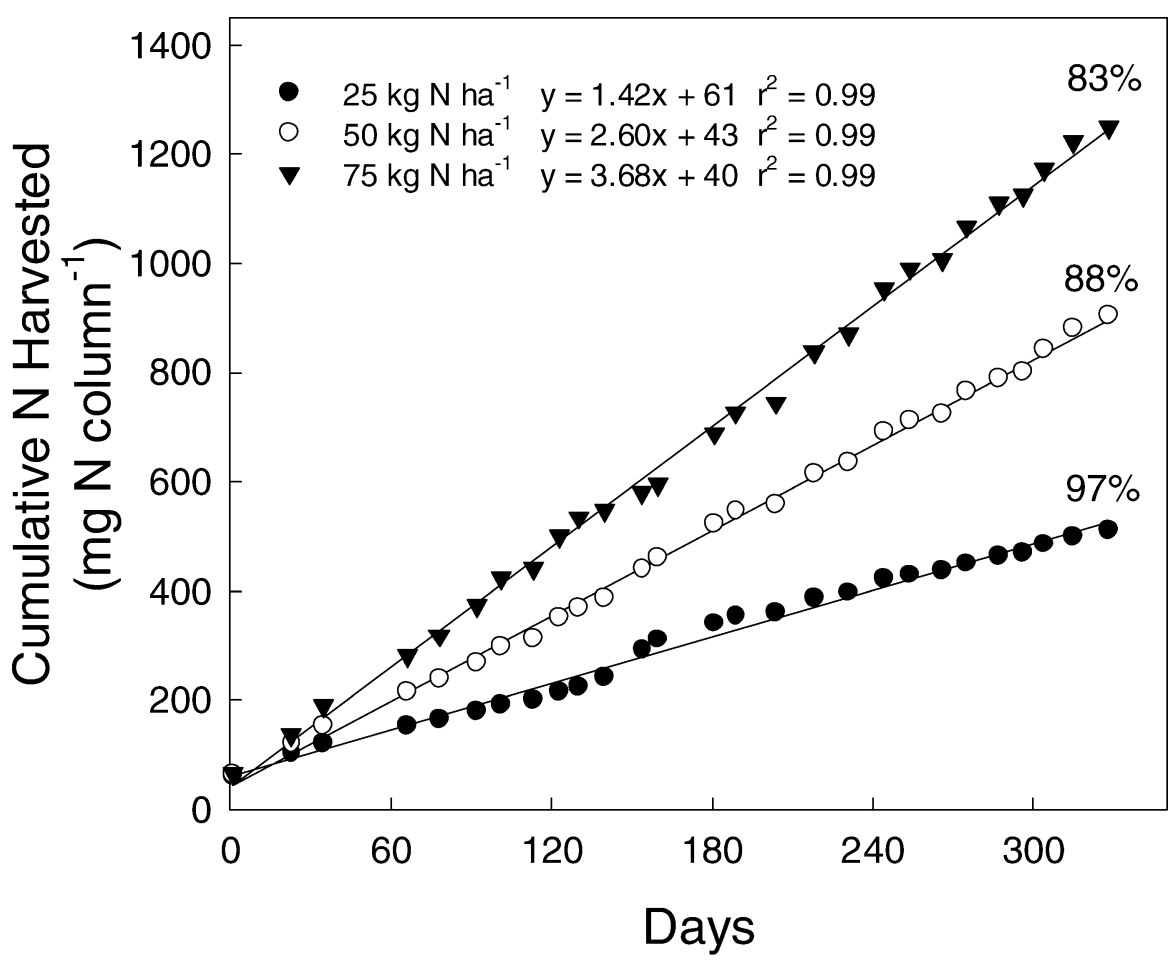

